\title{
Evaluation of different techniques in the diagnosis of Toxoplasma encephalitis
}

\author{
J. C. ROdRíguez, M. M. MARTínez*, A. R. MARTíneZ* and G. ROYO \\ Laboratory of Microbiology, General University Hospital of Elche, University of Alicante and *Department of \\ Parasitology, Faculty of Pharmacy, Complutense University, Madrid, Spain
}

\begin{abstract}
This study evaluated the detection of antibodies, circulating antigens and parasite DNA by polymerase chain reaction (PCR) in the diagnosis of toxoplasma encephalitis. The detection of antibody classes and IgG avidity were not useful diagnostically. The detection of circulating antigens by the ELISA system described was not sufficiently sensitive. The detection of DNA by PCR was the most useful test especially in untreated patients, with a sensitivity of $62 \%$ overall, $81 \%$ in untreated patients and only $20 \%$ in treated patients. The use of non-isotopic probes makes the use of this technique feasible in routine diagnostic parasitology laboratories.
\end{abstract}

\section{Introduction}

Toxoplasmosis is a parasitic disease that affects millions of people worldwide, although it is asymptomatic in the majority of cases. Nevertheless, it is of clinical significance when primary infection occurs or when there is reactivation of infection in immunosuppressed patients, e.g., AIDS patients.

The incidence of toxoplasma encephalitis is directly related to the prevalence of anti-toxoplasma antibodies in the population and the prevalence of HIV infection. The prevalence among HIV-positive patients in the USA varies from $15 \%$ to $40 \%$ [1] but increases to $96 \%$ in certain areas of Africa and Europe [2]. Approximately $45 \%$ of all HIV-positive individuals with toxoplasma antibodies develop toxoplasma encephalitis [3]. Therefore, in areas where antibodies against Toxoplasma gondii are prevalent, toxoplasma encephalitis may arise in $25-50 \%$ of HIV-positive patients [1]. However, the widespread use of cotrimoxazole prophylaxis against Pneumocystis carinii has reduced the incidence of cerebral toxoplasmosis significantly.

This study evaluated the diagnostic usefulness of detecting antibody classes, circulating antigens and parasite DNA by polymerase chain reaction (PCR) in the diagnosis of toxoplasmosis in HIV-positive patients.

Received 2 July 1996; revised version accepted 22 Nov. 1996.

Corresponding author: Dr J. C. Rodríguez.

\section{Materials and methods}

Patient groups

Group 1 comprised 70 asymptomatic and immunocompetent adult patients with previous $T$. gondii infection, i.e., evidence of antibodies detected by micro-agglutination (bioMérieux, Marcy L'Etoile, France) but without specific IgM (ISAGA, bioMérieux).

Group 2 comprised 70 immunocompetent patients with no specific antibodies to $T$. gondii detectable by the above techniques.

Group 3 comprised 63 HIV-positive patients with central nervous system pathology other than toxoplasma encephalitis (infectious and non-infectious processes).

Group 4 comprised 16 HIV-positive patients with brain lesions compatible with toxoplasma encephalitis. Toxoplasma encephalitis was considered likely when certain features were seen on CT scan and when there was a positive response to specific chemotherapy. Positive CT findings are multiple low-density areas without contrast and nodular enhancement or ring-like enhancement with contrast [4]. Patients in this group were divided into two subgroups as described below.

Group $4 a$ contained five patients who were receiving anti-toxoplasma therapy when cerebrospinal fluid (CSF) was obtained.

Group $4 b$ contained 11 patients who had not previously received specific treatment at the time CSF was obtained and who were not taking any anti-toxoplasma drugs as treatment or prophylaxis for $P$. carinii or Mycobacterium avium. 


\section{Specimen methodology}

Serum and CSF samples from each patient were stored at $-70^{\circ} \mathrm{C}$ until processed. Serum was assessed for circulating antibodies and antigens. CSF was assessed for antigens and toxoplasma DNA by PCR.

IgG, IgM and IgA were detected and assayed according to methods described previously [5-8]. Sera were diluted 1 in 250 to detect $\operatorname{IgG}$, and for the detection of $\operatorname{IgM}$ and $\operatorname{IgA}$, they were diluted to 1 in 100. Controls and cut-off points were provided by Sorin Biomedica (Saluggia, Italy). IgG avidity was assessed with a $T$. gondii $\mathrm{IgG}$ avidity kit (Menarini, Barcelona, Spain) as described previously $[9,10]$.

Circulating antigens were detected by an ELISA sandwich technique with two polyclonal antibodies. Hyperimmune antibodies were obtained by immunising rabbits and guinea-pigs with a sonicated preparation of tachyzoites from a $T$. gondii $\mathrm{RH}$ strain that had previously been purified by a lectin procedure (Sigma) [11]. The hyperimmune antibodies were purified by an ammonium sulphate and caprylic acid process [12]. Rabbit hyperimmune antibodies $(2 \mu \mathrm{g})$ were fixed on to an ELISA slide. Samples $(100 \mu \mathrm{l})$ were added and incubated at $37^{\circ} \mathrm{C}$ for $24 \mathrm{~h}$ and the presence of circulating antigens was detected by adding $2 \mu \mathrm{g}$ of guinea-pig hyperimmune antibody and incubation for $2 \mathrm{~h}$ at $37^{\circ} \mathrm{C}$. Anti-guinea-pig antibodies marked with peroxidase (Sigma) were then added and tetramethylbenzidin-dihydrochloride (TMB) and hydrogen peroxide were used in developing. Readings were taken at $450 \mathrm{~nm}$. The cut-off point used was the mean $+2 \mathrm{SD}$ of a group of serum samples taken from patients without $T$. gondii antibodies [13-15].

DNA was extracted for PCR by two procedures. In the first (A) CSF was centrifuged at $13000 \mathrm{~g}$ for $15 \mathrm{~min}$ and the sediment was resuspended in $80 \mu \mathrm{l}$ of buffer


proteinase $\mathrm{K}$ (Boehringer Mannheim, Germany) $800 \mu \mathrm{g}$ diluted in sterile distilled water $20 \mu \mathrm{l}$. After pre-incubation for $3 \mathrm{~h}$ at $56^{\circ} \mathrm{C}$, this mixture was incubated for $10 \mathrm{~min}$ at $100^{\circ} \mathrm{C}$.

In method (B), after amplification of the DNA extracted by the above procedure, the rest of the sample was subjected to a purification process consisting of extraction with phenol chloroform and subsequent DNA precipitation with isopropanol.

Fragments of the B1 gene, which is repeated 35 times within the $T$. gondii genome, (5'-GGA ACT GCA TCC GTT CAT GAG and 5'-TCT TTA AAG CGT TCG TGG TC) were used as primer oligonucleotides and amplification was by 40 cycles of $60 \mathrm{~s}$ at $94^{\circ} \mathrm{C}$, $90 \mathrm{~s}$ at $55^{\circ} \mathrm{C}$ and $60 \mathrm{~s}$ at $72^{\circ} \mathrm{C}$ [16]. A non-isotopic $5^{\prime}-$ GGC GAC CCA ATC TGC GAA TAC CAC C probe $(100 \mu \mathrm{g} / \mathrm{ml})$ was used, marked at the end with digoxigenin for developing, which was in contact with the sample overnight. This was then developed with a chemiluminescent compound (Luminescent Detection Kit for Nucleid Acids; Boehringer Mannheim, Germany) [17], according to the manufacturer's instructions, and chemoluminescence was detected by exposure of X-ray film (Fig. 1).

After purifying the tachyzoites as described above, several suspensions with different numbers of tachyzoites were prepared and then subjected to PCR. The minimum number of tachyzoites that could be detected with this technique was calculated and the detection limit was set at 5 tachyzoites/sample for each DNA extraction technique.

\section{Statistical methods}

For both sensitivity and specificity, the confidence interval was calculated for a ratio; therefore the exact method was used, based on the Snedecord $F$ or an approximation of the normal distribution of a binomial under appropriate conditions ( $\mathrm{np}>5$ and $\mathrm{n}[1-\mathrm{p}]>5$ ).

\section{Results}

\section{Antibody detection}

IgG was detected in all the serum samples from patients with toxoplasma encephalitis. Thirty-four of the 63 patients in group 3 had IgG antibodies. IgM was not detected in any of the samples. IgA was found in six of 70 immunocompetent patients with previous toxoplasmosis (group 1), in two of 63 patients without toxoplasma encephalitis (group 3) and in three of 16 HIV-positive patients with toxoplasma encephalitis (group 4). The sensitivity and specificity of IgA detection in the diagnosis of toxoplasma encephalitis were $18 \%$ and $94 \%$, respectively.

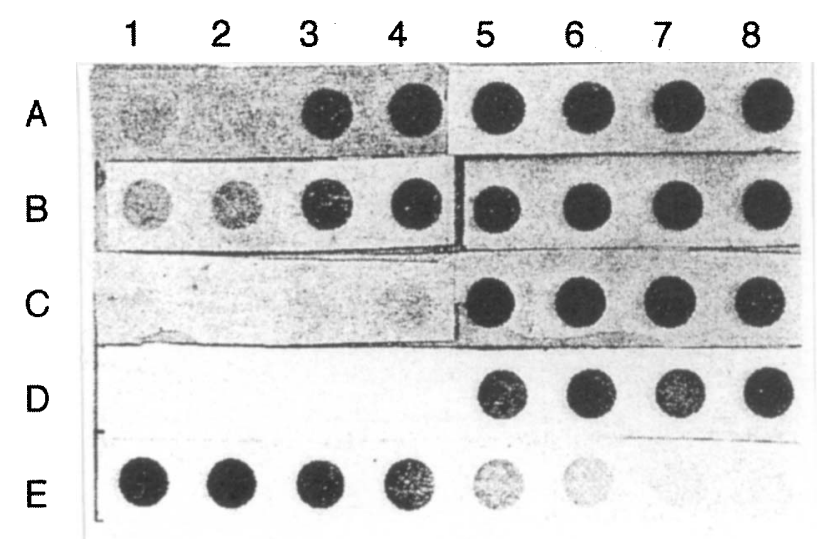

Fig. 1. Detection of chemoluminescence by X-ray film. Lanes A, B, C and D show DNA detection by PCR of clinical samples. The presence of parasite DNA in the sample is indicated by chemoluminiscence. Lane $\mathbf{E}$ corresponds to the calculation of the detection limits of this technique. 


\section{Avidity of $\operatorname{Ig} G$}

High avidity antibodies (indicative of previous infection) were present in 67 of 70 subjects in group 1 (immunocompetent with previous infection), in 31 of 34 patients in group 3 (HIV-positive patients without toxoplasma encephalitis) and in the 16 patients in group 4 (HIV-positive patients with toxoplasma encephalitis). Low avidity IgG antibodies were found in patients without circulating antigens and without other evidence of toxoplasma encephalitis and because of this, together with the absence of IgM, these results were considered as false positives.

\section{Antigen detection}

The results from the detection of circulating antigens in serum and CSF samples are shown in Table 1. The sensitivity and specificity in serum samples were $12 \%$ and $93 \%$, respectively. In CSF samples, the sensitivity was $6 \%$, while the specificity was $100 \%$.

\section{$P C R$}

The PCR results obtained in the detection of toxoplasma DNA are shown in Table 2. With extraction technique $\mathrm{A}$, the overall sensitivity was $62 \%$; for untreated subjects, sensitivity increased to $81 \%$, while in treated subjects this fell to $20 \%$. With extraction technique $\mathrm{B}$, the overall sensitivity was $50 \%$, reaching

Table 1. Circulating Toxoplasma antigen in serum and CSF

\begin{tabular}{|c|c|c|c|}
\hline \multirow{2}{*}{$\begin{array}{l}\text { Patient } \\
\text { group* }\end{array}$} & \multirow{2}{*}{$\begin{array}{l}\text { Number of } \\
\text { patients } \\
\text { tested }\end{array}$} & \multicolumn{2}{|c|}{ Number of positive results } \\
\hline & & CSF & Serum \\
\hline 1 & 70 & 0 & 5 \\
\hline 2 & 70 & 0 & 3 \\
\hline 3 & 63 & 0 & 6 \\
\hline 4 & 16 & 1 & 2 \\
\hline $4 a$ & 5 & 0 & 0 \\
\hline $4 b$ & 11 & 1 & 2 \\
\hline
\end{tabular}

*Patient groups: 1, immunocompetent patients with antibodies; 2, immunocompetent patients without antibodies; 3, HIV patients without Toxoplasma encephalitis; 4 , HIV patients with Toxoplasma encephalitis; $4 a$, treated; $4 b$, untreated.

Table 2. Comparison of two DNA extraction techniques used in PCR to diagnose toxoplasmosis

\begin{tabular}{lccc}
\hline & Number of & \multicolumn{2}{c}{ Number of positive PCR results with } \\
\cline { 3 - 4 } Patient & $\begin{array}{c}\text { patients } \\
\text { tested }\end{array}$ & $\begin{array}{c}\text { technique } \\
\text { Aroup }\end{array}$ & technique \\
\hline 1 & 70 & 0 & B $\dagger$ \\
2 & 70 & 0 & 0 \\
3 & 63 & 0 & 0 \\
4 & 16 & 10 & 0 \\
$4 \mathrm{a}$ & 5 & 1 & 8 \\
$4 \mathrm{~b}$ & 11 & 9 & 1
\end{tabular}

*Patient groups: 1, immunocompetent patients with antibodies; 2, immunocompetent patients without antibodies; 3, HIV patients without Toxoplasma encephalitis; 4, HIV patients with Toxoplasma encephalitis; $4 \mathrm{a}$, treated; $4 \mathrm{~b}$, untreated.

†see Materials and methods.
Table 3. Sensitivity and specificity of the different diagnostic techniques

\begin{tabular}{lcccc}
\hline Technique & $\begin{array}{c}\text { Sensitivity } \\
(\%)\end{array}$ & $95 \%$ CI & $\begin{array}{c}\text { Specificity } \\
(\%)\end{array}$ & $95 \%$ CI \\
\hline Antibody & & & & \\
Ig G (serum) & 100 & 1 & 48.8 & $41-55$ \\
Ig M (serum) & 0 & 0 & 100 & 100 \\
Ig A (serum) & 18 & 4,45 & 94 & $89-98$ \\
Avidity IgG & 0 & 0 & 94 & $89-99$ \\
Antigen & & & & \\
Ag (serum) & 12 & $1-42$ & 93 & $89-96$ \\
Ag (CSF) & 6 & $0-30$ & 100 & 100 \\
PCR (CSF) & & & & 100 \\
PCR (A) & 62 & $47-84$ & 100 & 100 \\
PCR (B) & 50 & $29-74$ & 100 & 100 \\
\hline
\end{tabular}

${ }^{*} \mathrm{~A}$ and $\mathrm{B}$ refer to extraction techniques.

$63 \%$ in untreated subjects but falling to $20 \%$ in treated subjects. Specificity in all cases was $100 \%$. Table 3 shows the sensitivity and specificity for the different techniques.

\section{Discussion}

Toxoplasma encephalitis poses a diagnostic problem that traditional serological methods rarely resolve. Therefore this study aimed to study different methods of diagnosis, including more recent approaches. The presence of $\operatorname{IgG}$ and the absence of $\operatorname{IgM}$ in the group of subjects with toxoplasma encephalitis parallels the results of Derouin et al., who studied a group of 62 patients and detected IgG in 61 and IgM in only three [18]. Similarly, Zufferey et al. studied 47 HIV-positive patients with toxoplasmic reactivation and found IgM in only $6 \%[19]$.

The detection of low avidity antibodies correlates well with primary infections. Thus, Holliman et al. have stated that when infection has occurred within the last 3 months, low avidity antibodies may be detected [9]. In the present study, $T$. gondii infections in immunosuppressed subjects were considered most likely to represent previous infection in the majority of cases.

In immunocompetent subjects, Jaqueti et al. detected IgA following the acute phase of the disease, but this did not correlate with acute $T$. gondii infection [20]. With regard to immunosuppressed patients, Zufferey et al. studied 47 HIV-positive patients with toxoplasma reactivation and found $\operatorname{IgA}$ in only $18 \%$ [19]. Patel et al. also assessed the IgA detection in HIV-positive patients and concluded that it was of limited value [21]. Pinon et al. studied HIV-positive patients with acute toxoplasmosis and found IgA in $38 \%$. However, in HIV-positive patients without acute toxoplasmosis, $\operatorname{IgA}$ was detected in only $12 \%$ of cases [22]. In the present study, IgA was detected in some immunocompetent patients (6 of 70 ) without acute $T$. gondii infection. In the diagnosis of acute toxoplasma encephalitis this technique had a sensitivity of $18 \%$ 
and a specificity of $96 \%$, similar to those reported by other authors, and its clinical usefulness is therefore limited. As has been stated elsewhere [23, 24], the detection of $\mathrm{IgG}$ antibodies is of limited value in the diagnosis of toxoplasma reactivation in HIV-positive patients, but the presence of IgG may be important in predicting prognosis.

The technique used in the present study for the detection of circulating antigens demonstrated low sensitivity for both CSF and serum and had a low specificity with serum samples. Dannemann et al. did a prospective study of antigenaemia in 11 serum samples from HIV-positive subjects and did not detect antigens in any patients, although two subjects had acute toxoplasma encephalitis [25]. Hassl et al. studied the presence of circulating antigens in serum and CSF samples from patients with stage III and IV HIV infection and detected circulating antigens in 32 serum samples from 20 patients by ELISA; antigenaemia correlated well with serological results and clinical symptoms [26]. However, in that study, strict criteria were not used in the diagnosis of toxoplasma encephalitis. Candolfi et al. studied 115 serum samples from 19 transplant recipients with clinical and serological evidence of toxoplasma reactivation [27]. Antigens were detected in eight of these patients before or concurrent with a rise in IgG. They believed that elevated levels of $\mathrm{IgG}$ eliminated the presence of antigen in the serum by forming immune complexes and that this indicated that the period of antigenaemia was very short [27]. Letillois et al. used monoclonal antibodies to detect toxoplasma antigen and compared this with surface antigens in HIV-positive subjects; they found a sensitivity of $30 \%$ and specificity of $92 \%$ [28]. The detection of circulating antigens as a diagnostic approach presents difficulties because of the need for standardisation of methods and the timing of samples. Therefore, its usefulness as a diagnostic tool is limited.

The detection of parasite DNA by PCR has emerged as a useful diagnostic tool. However, variations in technique can affect results. The present study found differences between the two DNA extraction techniques used, so in order to increase sensitivity, both methods should be used. As regards the amplified sequence, the one described by Burg et al. [16] was chosen, i.e., the BI gene which is repeated 35 times within the genome. Wastling et al. compared two sequences, one found in the gene that codes protein P30 of the tachyzoite and the other in gene B1. They concluded that use of the B1 sequence increased the sensitivity [29]. The detection limit of the present technique was five tachyzoites/ml of sample. This is similar to that reported by other authors. Burg et al. detected the presence of only one micro-organism when assessing parasites alone, while 10 tachyzoites were detected when a mixture of parasites and white blood cells in a ratio of one parasite: $10^{5}$ leucocytes was assessed [16]. Gross et al. detected the presence of 10 parasites in $100 \mu \mathrm{l}$ of sample with a great number of human cells [30].

Several authors have evaluated PCR as a diagnostic tool for toxoplasma encephalitis and in spite of the fact that they used different work protocols, the results are promising in all cases [31-34]. The detection of the amplified DNA fragment by chemiluminescent probes makes the procedure feasible in laboratories that do not have facilities for handling radioactive isotopes. Both techniques have similar sensitivity.

An important issue when evaluating PCR as a diagnostic tool for toxoplasma encephalitis is whether the patient is receiving specific treatment. As the results of the present study and those of other authors show [35], diagnostic sensitivity decreases when patients are receiving treatment and, furthermore, the results obtained by this technique may be affected by treatment for other infections such as $P$. carinii or $M$. avium (if treatment consists of drugs with antitoxoplasma activity). Therefore, the PCR appears to be the most promising approach in the diagnosis of toxoplasma encephalitis. The use of non-radioactive probes, without increasing the time needed to carry out the test, makes it feasible in routine diagnostic laboratories. However, it is important to be aware of the limitations of this technique, including the need for standardisation and the possibility of false negative results, especially in samples from patients receiving specific antibiotic treatment.

\section{References}

1. Luft BJ, Remington JS. Toxoplasmic encephalitis in AIDS. Clin Infect Dis 1992; 15: 211-222.

2. Wong SY, Israelski DM, Remington JS. AIDS-associated toxoplasmosis. In: Sande MA, Volverding PA (eds) The medical management of AIDS, 4th edn. Philadelphia, WB Sanders. 1995; 460-493.

3. Zangerle R, Allerberger F, Pohl P, Fritsch P, Dierich MP. High risk of developing toxoplasmic encephalitis in AIDS patients seropositive to Toxoplasma gondii. Med Microbiol Immunol 1991; 180: 59-66.

4. Porter SB, Sande MA. Toxoplasmosis of the central nervous system in the acquired immunodeficiency syndrome. $N$ Engl J Med 1992; 327: 1643-1648.

5. Joynson DHM, Payne RA, Balfour AH, Prestage ES, Fleck DG. Five commercial enzyme linked immunosorbent assay kits for toxoplasma specific IgM antibody. J Clin Pathol 1989; 42: $653-657$

6. Wilson M, Ware DA, Walls KW. Evaluation of commercial serodiagnostic kits for toxoplasmosis. J Clin Microbiol 1987; 25: 2262-2265.

7. Verhofstede C, Van Renterghem L, Plum J. Comparison of six commercial enzyme linked immunosorbent assays for detecting IgM antibodies against Toxoplasma gondii. J Clin Pathol 1989; 42: $1285-1290$.

8. Del Bono V, Canessa A, Bruzzi P, Fiorelli MA, Terragna A. Significance of specific immunoglobulin $M$ in the chronological diagnosis of 38 cases of toxoplasmic lymphadenopathy. $J$ Clin Microbiol 1989; 27: 2133-2135.

9. Holliman RE, Raymond R, Renton N, Johnson JD. The diagnosis of toxoplasmosis using IgG avidity. Epidemiol Infect 1994; 112: 399-408. 
10. Lappalainen M, Koskela P, Koskiniemi M, et al. Toxoplasmosis acquired during pregnancy: improved serodiagnosis based on avidity of IgG. J Infect Dis 1993; 167: 691-697.

11. Hoshino-Shimizu S, Mineo JR, Camargo MA. Lectin used in the purification process of Toxoplasma gondii tachyzoites. $J$ Parasitol 1980; 66: 989-991.

12. Sambrook J, Fritsch EF, Maniatis $\mathrm{T}$ (eds). Molecular cloning a laboratory manual, 2nd edn. Cold Spring Harbor, NY Cold Spring Harbor Laboratory Press. 1989: 12-13.

13. van Knapen F, Panggabean SO, van Leusden J. Evaluation of laboratory diagnosis of toxoplasmosis by means of an ELISAtriple test. Detection of class specific IgG, IgM and circulating antigens. Anlonie van Leeuwenhoek 1986; 52: 5-13.

14. Turunen HJ. Detection of soluble antigens of Toxoplasma gondii by a four-layer modification of an enzyme immunoassay. $J$ Clin Microbiol 1983; 17: 768-773.

15. Lindenschmidt EG. Enzyme-linked inmunosorbent assay for detection of soluble Toxoplasma gondii antigen in acute-phase toxoplasmosis. Eur J Clin Microbiol 1985; 4: 488-492.

16. Burg JL, Grover CM, Pouletty P, Boothroyd JC. Direct and sensitive detection of a pathogenic protozoan, Toxoplasma gondii, by polymerase chain reaction. J Clin Microbiol 1989; 27: $1787-1792$.

17. Malloy D, Nauman RK, Paxton H. Detection of Borrelia burgdorferi using the polymerase chain reaction. $J$ Clin Microbiol 1990; 28: 1089-1093.

18. Derouin F, Thulliez P, Garin YJ. [Value and limitations of toxoplasmosis serology in HIV patients.] Pathol Biologie (Paris) 1991; 39: 255-259.

19. Zufferey J, Sugar A, Rudaz P, Bille J, Glauser MP, Chave JP. Prevalence of latent toxoplasmosis and serological diagnosis of active infection in HIV-positive patients. Eur J Microbiol Infect Dis 1993; 12: $591-595$.

20. Jaqueti J, Nicolas D, Navarro Gallar F. [Persistence of IgA antibodies against Toxoplasma gondii with ELISA.] Med Clin (Barcelona) 1994; 103: 197.

21. Patel B, Young Y, Duffy K, Tanner RP, Johnson J, Holliman RE. Immunoglobulin-A detection and the investigation of clinical toxoplasmosis. J Med Microbiol 1993; 38: 286-292.

22. Pinon JM, Foudrinier F, Mougeot G et al. Evaluation of risk and diagnostic value of quantitative assays of anti-Toxoplasma gondii immunoglobulin $\mathrm{A}(\operatorname{Ig} \mathrm{A}), \operatorname{IgE}$, and $\operatorname{IgM}$ and analytical study of specific IgG in immunodeficient patients. $J$ Clin Microbiol 1995; 33: 878-884.

23. Holliman RE. Serological study of the prevalence of toxoplasmosis in asymptomatic patients infected with human immunodeficiency virus. Epidemiol Infect 1990; 105: 415-418.

24. Grant IH, Gold JWM, Rosenblum M, Niedzwiecki D, Armstrong D. Toxoplasma gondii serology in HIV-infected patients: the development of central nervous system toxoplasmosis in AIDS. AIDS 1990; 4: 519-521.

25. Dannemann BR, Israelski DM, Leoung GS, McGraw T, Mills J, Remington JS. Toxoplasma serology, parasitemia and antigenemia in patients at risk for toxoplasmic encephalitis. AIDS 1991; 5: 1363-1365.

26. Hassl A, Aspock H, Flamm H. Circulating antigen of Toxoplasma gondii in patients with AIDS: significance of detection and structural properties. Zentralbl Bakteriol Mikrobiol Hyg A 1988; 270: 302-329.

27. Candolfi E, Derouin F, Kien T. Detection of circulating antigens in immunocompromised patients during reactivation of chronic toxoplasmosis. Eur J Clin Microbiol 1987; 6: 44-48.

28. Letillois MF, Laigle V, Santoro F, Micoud M, Chumpitazi BFF. Toxoplasma gondii surface antigen-1 in sera of HIV-infected patients as an indicator of reactivated toxoplasmosis. Eur $J$ Clin Microbiol Infect Dis 1995; 14: 899-903.

29. Wastling JM, Nicoll S, Buxton D. Comparison of two gene amplification methods for the detection of Toxoplasma gondii in experimentally infected sheep. $J$ Med Microbiol 1993; 38: $360-365$.

30. Gross U, Roggenkamp A, Janitschke K, Heesemann J. Improved sensitivity of the polymerase chain reaction for detection of Toxoplasma gondii in biological and human clinical specimens. Eur J Clin Microbiol Infect Dis 1992; 11: $33-39$

31. Cristina N, Pelloux H, Goulhot C, Brion JP, Leclercq P, Ambroise Thomas PTI. Detection of Toxoplasma gondii in AIDS patients by the polymerase chain reaction. Infection 1993; 21: $150-153$.

32. Østergaard L, Nielsen AK, Black FT. DNA amplification on cerebrospinal fluid for diagnosis of cerebral toxoplasmosis among HIV-positive patients with signs or symptoms of neurological disease. Scand J Infect Dis 1993; 25: 227-237.

33. Schoondermark-van de Ven E, Galama J, Kraaijeveld C, van Druten J, Meuwissen J, Melchers W. Value of the polymerase chain reaction for the detection of Toxoplasma gondii in cerebrospinal fluid from patients with AIDS. Clin Infect Dis 1993; 16: 661-666.

34. Lebech M, Lebech A-M, Nelsing S, Vuust J, Mathiesen J, Petersen E. Detection of Toxoplasma gondii DNA by polymerase chain reaction in cerebrospinal fluid from AIDS patients with cerebral toxoplasmosis. J Infect Dis 1992; 165: 982-983.

35. Novati R, Castagna A, Morsica G et al. Polymerase chain reaction for Toxoplasma gondii DNA in the cerebrospinal fluid of AIDS patients with focal brain lesions. AIDS 1994; 8: $1691-1694$. 